\title{
Substrate Purity Effect on the Defect Formation and Properties of Amorphous Anodic Barrier $\mathrm{Al}_{2} \mathbf{O}_{3}$
}

\author{
Miriam González-Castaño, ${ }^{1, z}$ Max Döbeli, ${ }^{2}$ Vicente Araullo-Peters, ${ }^{1}$ Lars P. H. Jeurgens, ${ }^{1}$ \\ Patrik Schmutz, ${ }^{1, *}$ and Claudia Cancellieri ${ }^{1} 1$
}

\author{
${ }^{1}$ EMPA, Swiss Federal Laboratories for Materials Science and Technology, Laboratory for Joining Technologies and \\ Corrosion, Dübendorf, Zürich 8600, Switzerland \\ ${ }^{2}$ Ion Beam Physics, ETH Zürich, CH-8093 Zürich, Switzerland
}

\begin{abstract}
A comprehensive study concerning the effect of different $\mathrm{Al}$ metal substrate purities (i.e. 99.5 versus $99.99 \%$ ) on the properties of amorphous anodic barrier $\mathrm{Al}_{2} \mathrm{O}_{3}$ is presented. The experimental findings demonstrate that only tiny variations in the purity of the employed $\mathrm{Al}$ materials lead to different oxide growth rate, surface charge, structural defect and impurities content. Below the ionic recombination potential characterized by Scanning Kelvin Probe Force Microscopy, an increase of the anodizing voltage leads to an improvement of the oxide barrier properties. The larger growth rate exhibited by the higher purity Al substrate however indicates the formation of highly disordered and inhomogeneous barrier oxides. A combination of photoelectrochemical and photoluminescence spectroscopies was used to characterize structural defect concentration and confirmed the presence of significantly higher concentrations in the oxide grown on the purer Al substrates. FT-IR and RBS/ERDA results indicate that $\mathrm{H}$ and $\mathrm{C}$ species are incorporated from the electrolyte solution in the barrier oxides with higher $\mathrm{H}$ amounts detected in the oxide grown on the purer $\mathrm{Al}$ substrate.

(C) The Author(s) 2018. Published by ECS. This is an open access article distributed under the terms of the Creative Commons Attribution 4.0 License (CC BY, http://creativecommons.org/licenses/by/4.0/), which permits unrestricted reuse of the work in any medium, provided the original work is properly cited. [DOI: 10.1149/2.1161807jes]

(cc) BY
\end{abstract}

Manuscript submitted February 26, 2018; revised manuscript received May 7, 2018. Published May 23, 2018.

The outstanding chemical and physical properties of $\mathrm{Al}_{2} \mathrm{O}_{3}$ make it a very attractive material for numerous technological applications. ${ }^{1,2}$ For instance, porous $\mathrm{Al}_{2} \mathrm{O}_{3}$ is widely applied as a catalyst support because of its thermal stability and heat conductivity. ${ }^{3-7}$ Dense and compact $\mathrm{Al}_{2} \mathrm{O}_{3}$ layers (i.e. without porosity and thus, with a much lower specific surface area) are also of great industrial importance, particularly, for protective and decorative coatings. ${ }^{8}$ Additionally, the high electrical insulation displayed by barrier $\mathrm{Al}_{2} \mathrm{O}_{3}$ layers has raised interest in the microelectronics community to apply them as dielectric capacitors. ${ }^{8-10}$ The functionality and performance of such barrier-type oxide layers generally depend on multiple factors, such as layer thickness, composition, morphology, density, impurities and/or residual stresses. ${ }^{11}$

Industrially, barrier $\mathrm{Al}_{2} \mathrm{O}_{3}$ oxides of well-defined thicknesses are commonly produced by anodizing a parent metal or alloy substrate in an electrolyte solution under the influence of an externally applied electric field. ${ }^{12}$ Oxide-layer growth then proceeds by in- and outward migration of ionic species and their vacancies, as well as electrons and holes, across the developing oxide layer under the influence of the applied anodizing voltage, $V_{\text {anod }}$. Importantly, in parallel, impurity species from the electrolyte and/or the metal (or alloy) substrate may be incorporated into the growing oxide layer. ${ }^{13,14}$ The resulting performance of these anodically grown barrier oxide layers (e.g. corrosion resistance, electrical insulation, surface protection) strongly depends on the type, concentration and spatial distribution of such incorporated impurity species within the barrier oxide layer. ${ }^{3,15-18}$ Notably, such impurities can either improve or deteriorate the oxide barrier properties. Accordingly, intentional incorporation of impurities in anodic $\mathrm{Al}_{2} \mathrm{O}_{3}$ layers is widely employed for tailoring the oxide properties: ${ }^{6,8,19}$ e.g. the presence of small amounts of $\mathrm{Cr}(\mathrm{VI})$ enhances the corrosion resistance of $\mathrm{Al}_{2} \mathrm{O}_{3} ;{ }^{20,21}$ the addition of $\mathrm{Zr}$ or $\mathrm{Y}$ to $\mathrm{Al}_{2} \mathrm{O}_{3}$ enhances the thermal resistance against sintering.

Anodizing of metals and alloys in organic electrolytes of controlled $\mathrm{pH}(5-7)$, such as oxalic and citric acids, generally results in the formation of dense and low-defective barrier oxide layers with relatively low electrolyte impurity concentrations. ${ }^{11,22,23}$ Nevertheless, the incorporation of minor impurity concentrations from the electrolyte solution into the grown $\mathrm{Al}_{2} \mathrm{O}_{3}$ barrier layer seems unavoidable. For organic/aqueous electrolyte solutions, $\mathrm{H}$ - and $\mathrm{C}$ - containing species

*Electrochemical Society Member.

${ }^{\mathrm{z}}$ E-mail: mirian.gonzalez-castano@empa.ch are the main impurities in the anodically grown oxide layer. The incorporation of $\mathrm{OH}$ and/or $\mathrm{H}$ into $\mathrm{Al}_{2} \mathrm{O}_{3}$ barrier layers is known to affect the electrical insulation characteristics, ${ }^{24}$ while incorporation of $\mathrm{H}$ species at the metal/oxide interface may increase the susceptibility of $\mathrm{Al}_{2} \mathrm{O}_{3}$ barrier layers to pitting corrosion. ${ }^{25}$ The integration of $\mathrm{C}$ species increases the concentration of defective centers in $\mathrm{Al}_{2} \mathrm{O}_{3}$ and affects its optical and electrical properties. ${ }^{26}$

The aim of this work is to evaluate the impact of $\mathrm{Al}$ substrate purity on the structural properties (density, defect level) of anodic $\mathrm{Al}_{2} \mathrm{O}_{3}$ barrier layers. Relationships between the generated defects during anodic growth, density related ionic migration properties measured by AFM-SKPFM and impurity concentration level found within to the barrier oxides is established. Characterization of the oxide electronic and optical properties by combined photoelectrochemistry and photoluminescence is shown as a very sensitive methodology to track the structural defect concentration. Indeed, tuning of the properties of anodically grown $\mathrm{Al}_{2} \mathrm{O}_{3}$ barrier layers requires fundamental knowledge and engineering know-how. For this purpose, two typical Al sheet purities of $99.5 \%$ and $99.99 \%$, as widely employed in various fields from light weight applications to microelectronics, are anodized in $0.1 \mathrm{M}$ citric acid $(\mathrm{pH}=5.8)$ for different anodizing potentials in the range of 50 to $200 \mathrm{~V}$. This resulted in the formation of overall stoichiometric $\mathrm{Al}_{2} \mathrm{O}_{3}$ barrier layers with various thicknesses in the range of 50 to $300 \mathrm{~nm}$. Atomic Force Microscopy based Scanning Kelvin probe force microscopy (AFM-SKPFM) is employed to obtain information on the surface roughness and surface potential of the grown oxide layers. Rutherford Backscattering (RBS) and Fourier Transformed Infrared (FT-IR) spectroscopy techniques are applied to investigate the type and concentration of impurities in the grown oxide layers. The relationships between the substrate purity, the electronic and structural defects, as well as the incorporated $\mathrm{H}$ - and $\mathrm{C}$-based impurity concentrations are disclosed. Contrary to intuition, anodizing of the purer $\mathrm{Al}$ substrates results in less dense and more defective barrier oxides, which also contain a higher content of impurity species from the electrolyte solution.

\section{Experimental: Materials and Methods}

Anodizing surface treatments were performed for two commonlyused $\mathrm{Al}$ substrate purities of $99.5 \%$ and $99.99 \%$, further referred to as A199.5 and A199.99, respectively. The main impurities of the A199.99 substrate are $0.00041 \% \mathrm{Cu}, 0.00035 \% \mathrm{Fe}$ and $0.00041 \%$ $\mathrm{Si}$. The A199.5 has higher impurity concentrations of $0.2 \% \mathrm{Fe}$ and 

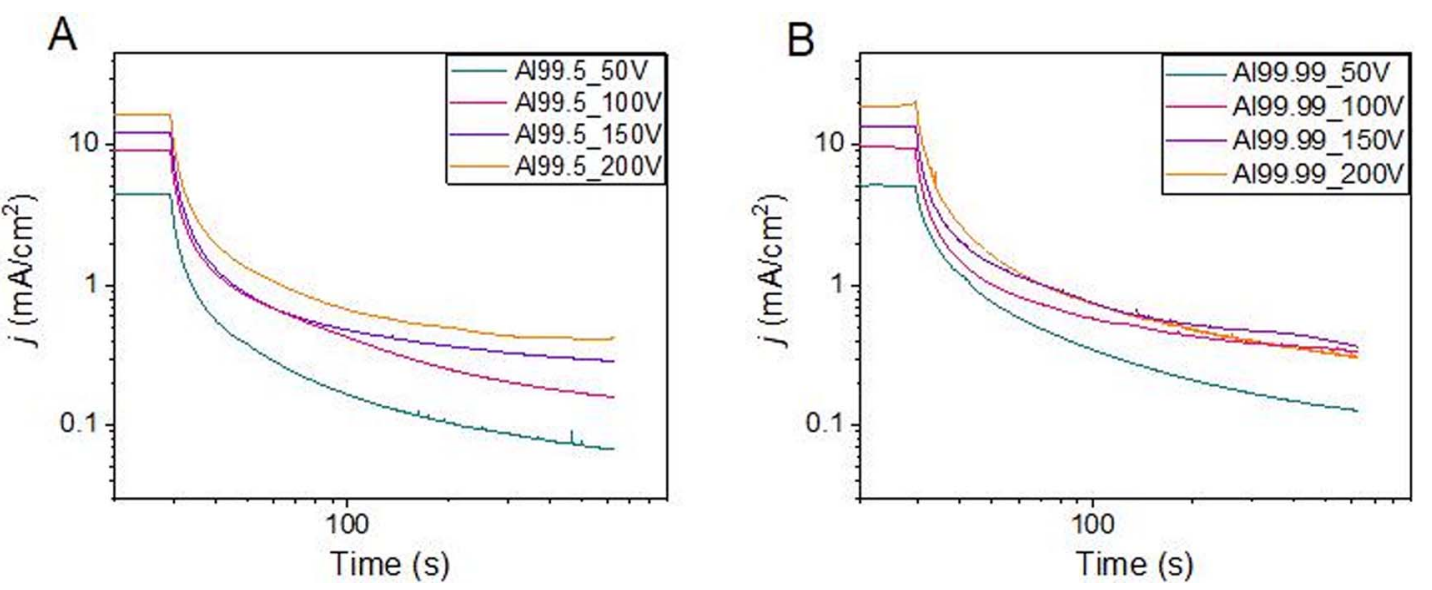

Figure 1. Current transient profiles obtained during the anodizing experiments at different voltages ( $30 \mathrm{~s}$ ramp, $60 \mathrm{~s}$ holding time) for both type of polished samples: A) Al 99.5; B) A199.99.

$0.2 \% \mathrm{Si}$. Both metallic substrates were mirror-like polished by subsequent grinding (until $\mathrm{P} 4000$ grit with $\mathrm{SiC}$ paper) and final polishing with diamond paste down to $1 \mu \mathrm{m}$. On some selected samples, electropolishing surface finish was performed in acidic solutions composed by $\mathrm{HClO}_{4}$ in $\mathrm{EtOH}(1: 3 \mathrm{v} / \mathrm{v})$ at $20 \mathrm{~V}$ during 2 minutes. Prior to the anodizing, the substrates were ultrasonically cleaned in ethanol, rinsed with milli-Q water and then dried with pure Ar gas. Potentiostatic anodizing was performed using a two-electrode electrochemical cell with a Pt rod as the cathode and a Keithley power source Model 2400. The anodic oxidations were performed in an $0.1 \mathrm{M}$ citric acid $(\mathrm{pH}=5.8)$ electrolyte at room temperature for a defined area of $1 \mathrm{~cm}^{2}$ and at a fixed anodizing voltage ( $\left.V_{\text {anod }}\right)$ of $50,100,150$ or $200 \mathrm{~V}$, while applying a ramp and dwell time of $30 \mathrm{~s}$ and $600 \mathrm{~s}$, respectively. For the remainder of the paper, the following terminology will be used: e.g. an A199.9 substrate anodized at $V_{\text {anod }}=50 \mathrm{~V}$ is labeled A199.99_50 V.

The average oxide layer thickness was measured by spectroscopic ellipsometry using a M-2000 of J.A. Woollam Co. Inc for three different angles between the incident and detected beam of $\alpha_{1}=50^{\circ}, \alpha_{2}=$ $60^{\circ}$, and $\alpha_{3}=70^{\circ}$. For each angle, the UV-Vis spectra were collected in the wavelength range of $370-1720 \mathrm{~nm}$ with an integration times of $5 \mathrm{~s}$. The layer thickness was evaluated from the measured series of spectra, according to an established procedure. ${ }^{22}$

Atomic-Force-Microscopy-based Scanning Kelvin probe force microscopy (AFM-SKPFM) was employed to gain information on the surface potential and surface roughness of the anodized oxide layers. The surface characterizations were performed with a Bruker Nano Environmental AFM (E-SCOPE) system using a Pt-Ir metallic coated tip with a resonance frequency of $f_{\text {res }}=100 \mathrm{kHz}$ and a nominal spring constant $\mathrm{k}=2.8 \mathrm{Nm}^{-1}$. After the topography determination in tapping mode, the tip was lifted off from the surface at a distance of $50 \mathrm{~nm}$ and an AC voltage of $1 \mathrm{~V}$ was applied on the Pt-Ir coated silicon tip (SCM-PIT). An additional DC voltage was superposed on the AC oscillation of the tip and nulling of the signal was performed with the help of a lock-in amplifier. At any point of the surface, the obtained potential was related to the local Volta potential difference (VPD) between the tip and the sample and mapping of the VPD allows the characterization of the local heterogeneities of the oxide. In the case of a "semiconducting" oxide, electronic space charge can be an important contribution to the measured potential, but also ionic defect distribution across the oxide will add a contribution and this aspect is the focus of the AFM-SKPFM analysis. The surface potential is referred to a pure Ni surface previously immersed in distilled water. ${ }^{27}$

Photoelectrochemical (PEC) characterization was performed using a three electrode cell setup connected to a Jaissle PotentiostatGalvanostat Model 1002-T-NC. The electrochemical flat cell included a quartz optical window, a Pt wire as counter, a calomel reference electrode and the anodized samples as working electrode in contact to the electrolyte. The light irradiation system was composed of a UV enhanced $150 \mathrm{~W}$ Xenon lamp and a LOT-ORIEL monochromator. The small contribution of dark current photoeffects was accounted for and subtracted with the use of a mechanical chopper $(17 \mathrm{~Hz})$ coupled to a lock-in amplifier to obtain the differential electrochemical signal between lamp and ambient illumination. Current spectra data from the photoelectrochemical measurements were recorded at $0.1 \mathrm{~V}$ above the OCP and automatically corrected for the lamp spectral sensitivity using a home-made Lab-View software interface.

Photoluminescence (PL) spectroscopy was performed using a Horiba Jobin Yvon Fluorolog spectrometer equipped with a Xe lamp. The system also contains two monochromators and slits that allow controlling the excitation and measuring energy ranges and intensities, respectively. For all the samples, the presented spectra were corrected by the spectral sensitivity of the system. The anodized samples were excited at $260 \mathrm{~nm}$ and the recorded emission spectra were confined between 305 and $340 \mathrm{~cm}^{-1}$ with an integration time of $4 \mathrm{~s}$. The presented spectra were all background corrected.

Rutherford Backscattering Spectrometry (RBS) measurements ${ }^{28}$ were performed at the Laboratory of Ion Beam Physics at the ETH Zurich using a $2 \mathrm{MeV} 4 \mathrm{He}$ beam and a silicon PIN diode detector under $168^{\circ}$. The collected data were evaluated using the RUMP program. ${ }^{29}$ To measure hydrogen depth profiles, Elastic Recoil Detection (ERD) experiments have been carried out with the same $4 \mathrm{He}$ beam with a PIN diode detector under $30^{\circ}$ scattering angle using a Mylar absorber foil. ${ }^{28}$ Absolute concentrations were normalized to a mica standard with 9.5 at\% hydrogen. Carbon depth profiles were determined by Heavy Ion Elastic Recoil Detection Analysis (ERDA). ${ }^{30}$ A $13 \mathrm{MeV}$ 127I projectile beam was used under $18^{\circ}$ incidence angle and scattered recoils were identified by the combination of a time-of-flight spectrometer with a gas ionization chamber under a scattering angle of $36^{\circ}$. The data was converted into quantitative concentration depth profiles by means of the Data Furnace code. ${ }^{31}$

Fourier Transmission Infrared (FT-IR) spectra were recorded on a Varian Cary 50 UV-Vis spectrophotometer in the range of 4000 to $500 \mathrm{~cm}^{-1}, 64$ accumulations by scan and $4 \mathrm{~cm}^{-1}$ of spectra resolution. The presented spectra were all baseline corrected.

The high resolution Scanning Electron Microscopy (SEM) cross sections were collected on an FEI Helios 660 system in secondary electron imaging mode using a $2 \mathrm{keV}$ electron beam at a working distance of $4 \mathrm{~mm}$. The Focused Ion Beam (FIB) cross sections of the anodized oxide were prepared in two steps. A region of interest was protected using electron beam and ion-beam-assisted deposition of a platinum layer. The cross section was then created using focused ion beam cuts.

\section{Results}

Anodic oxide growth and morphology.-Figure 1 shows the anodic oxidation current response recorded for both polished substrate purities during the anodizing processes, applying a constant $30 \mathrm{~s}$ voltage ramp and $600 \mathrm{~s}$ final voltage dwell. For each substrate purity and anodizing voltage, typical current transient profiles for anodic barrier 
A

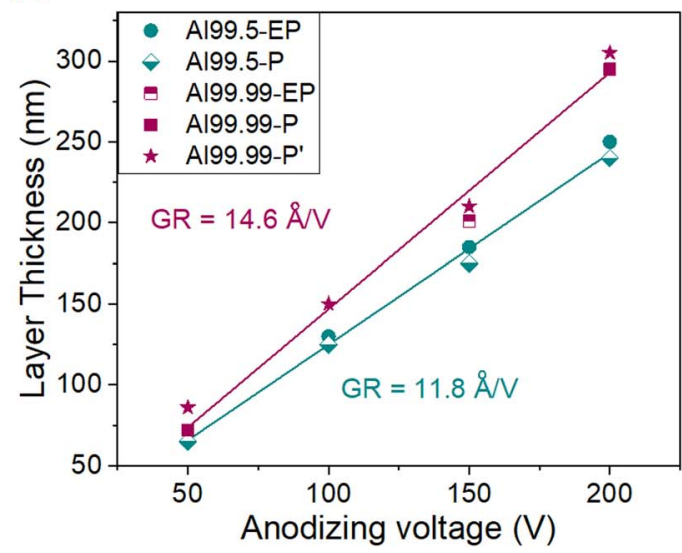

B
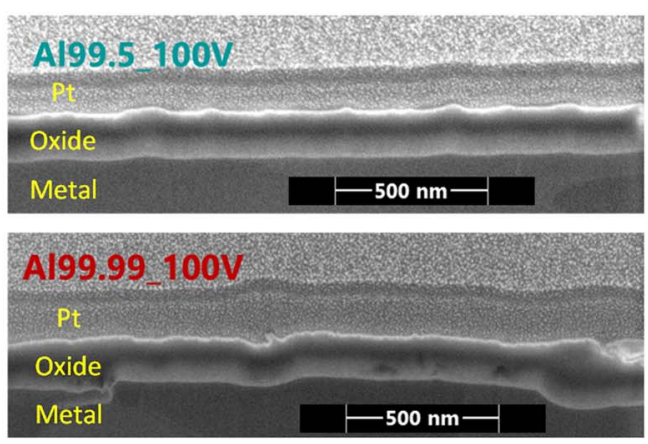

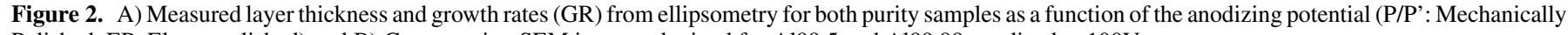
Polished, EP: Electropolished) and B) Cross section SEM images obtained for A199.5 and A199.99 anodized at 100V.

layer growth are observed. During voltage ramping, the measured current was related to the formation and growth of a barrier oxide layer induced by the electrical field and the consequent opposite migration of ionic species through the thickening oxide. Both substrate purities exhibited an initial current response proportional to the anodizing voltage. The electric field across the growing oxide decreases approximately linearly with increasing thickness of the formed oxide layer. Once the final voltage was reached, a limiting oxide layer thickness was established. As reflected by the exponential decay of the anodizing current in Figure 1, the electric-field-driven ionic migration of reactants through the oxide layer (i.e. cations, anions and their vacancies) ceased. Then, as long as the maximum applied anodizing voltage is maintained (dwell time), structural relaxations (e.g. local atomic cluster ordering and densification) combined with the recombination of local charges in the grown oxide layer may occur by redistribution of ionic and defect species under the influence of the maintained electrical field, giving rise to the observed residual current. Due to the short dwell times employed (10 min), proper evaluations of the current decay characteristic of high field growth models are hindered. Qualitatively, it can still be observed that very different current decay behaviors occurred. A faster decay was found for the A199.5 anodized at $50 \mathrm{~V}$ corresponding to an effective ionic mobility and oxide structure stabilization. Interestingly, when the anodizing voltage was increased for the A199.5 substrate, the residual current after the initial exponential decay stayed quite high especially for the 150 and $200 \mathrm{~V}$ most probably due to delayed migration of ionic species. For the A199.99 substrate, a different behavior was observed with much less dependence of the current decay on the applied anodizing potential above $100 \mathrm{~V}$. The similarity of the curves recorded for 100, 150 and $200 \mathrm{~V}$ could be related to a similar higher migration behavior.

The grown barrier oxides were overall stoichiometric as characterized by RBS (i.e. $\mathrm{Al}_{2} \mathrm{O}_{3}$ ) and amorphous, in line with previous findings. ${ }^{22}$ For the A199.5 substrate, higher final current densities after $600 \mathrm{~s}$ dwell time were observed for increasing $V_{\text {anod }}$ (Figure 1A). The increase of the residual current with the $V_{\text {anod }}$ is typical for the growth of compact, barrier-type oxide layers, in which ionic migration and related space charge recombination processes are effectively hindered. ${ }^{22}$ The monotonous increase of measured final current observed for the A199.5 substrate contrast with the behavior for the A199.99 substrate, which exhibited an increase of the residual current density up to $150 \mathrm{~V}$; a further increment of the applied $V_{\text {anod }}$ to $200 \mathrm{~V}$ resulted in a slight drop of the residual final current density (Figure 1B). The detected drop in the final current density at high applied voltage suggests that the A199.99_200 V oxide layer possessed a less dense, oxide structure than the ones grown at lower anodizing voltages. In general, the final residual currents were smaller for the A199.5 substrate (except at $200 \mathrm{~V}$ ).
Figure 2A shows the anodized layer thickness obtained by ellipsometry for several A199.99 and A199.5 substrate for which different surface pretreatments e.g. electropolished (EP) and polished (P).No significant changes in the layer thickness are observed for each substrate purity when $\mathrm{P}$ and EP pretreatments are compared. In the case of A199.99 substrate, $\mathrm{P}$ and $\mathrm{P}^{\prime}$ indicate different polishing procedures with average roughness $\left(\mathrm{R}_{\mathrm{a}}\right)$ of about $10-15$ and 5-7 nm, respectively. Similar oxide thicknesses as function of anodizing voltages are also obtained for both initial surface roughness (A199.99-P and A199.99- $\mathrm{P}^{\prime}$ ).

For comparable anodizing voltages, thicker oxide layers are systematically formed on the A199.99 substrate for both polished and electropolished samples. In very good agreement to Figure 1, the higher layer thicknesses observed for all the A199.99 samples undoubtedly demonstrates that the different growth rates observed between the A199.99 and A199.5 substrates are related to the substrate purity and not to other surface differences (nanoscale roughness, pretreatment). For all the investigated conditions the average growth rates (GR) estimated for the A199.99 and A199.5 substrates are 14.6 $\mathrm{\AA} / \mathrm{V}$ and $11.8 \AA / \mathrm{V}$, respectively. Comparable anodic growth rates have been previously reported for $99.99 \% \mathrm{Al}$ foils. ${ }^{32}$ The small $\mathrm{Si}$ and $\mathrm{Fe}$ amounts present in the A199.5 metal substrates should account for the thinner oxides grown on this substrate; hindered growth rates have clearly been observed at higher $\mathrm{Si}$ concentrations (above $4 \% \mathrm{Si}$ ) on Al-Si alloys PVD thin film. ${ }^{33}$

Even if no differences in oxide growth rate could be evidenced by ellipsometry between P and EP pretreated A199.5 substrates, AFMSKPFM measurements (section AFM-SKPFM) showed large scatter between samples in the VPD evolution for oxides grown on electropolished A199.5 substrates. This scattering could be related to very small $\mathrm{Si}$ enrichment on the surface resulting from electropolishing and relevant to the oxide structural defect generation. ${ }^{33}$ In order to avoid the uncertainties (e.g. compositional surface enrichment in the $\%$ range as a function of the preparation conditions) that EP pretreatment can introduce on A199.5 samples, the present study is focused on anodic oxidation of mechanically polished A199.5 and A199.99 samples. The SEM characterization performed on focused ion beam cross sections of selected polished A199.99 and Al99.5 samples are shown in the Figure 2B. In concordance with ellipsometry, thicker oxide layers were formed on the A199.99 substrate. For instance, average oxide layer thicknesses of $155 \pm 5 \mathrm{~nm}$ and $133 \pm 2 \mathrm{~nm}$ were determined for the A199.99_100 V and A199.5_100 V substrate, respectively. The cross-sectional SEM micrographs also reveal small, but distinct, morphological differences between the oxide layers grown on the two types of substrate. In comparison to A199.5 substrates, the oxide layers on A199.99 present more heterogeneity (dark secondary electron emission spots) in the oxide. The softer A199.99 substrate also 
A

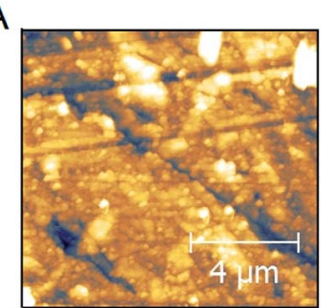

C

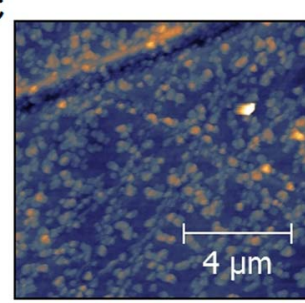

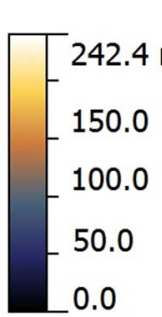

$\mathrm{B}$
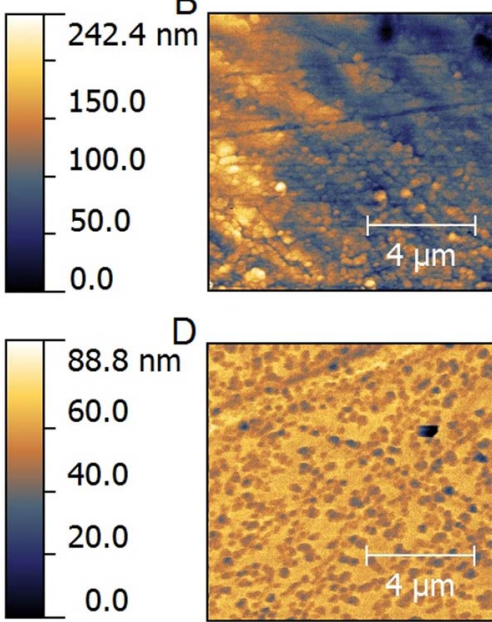

D

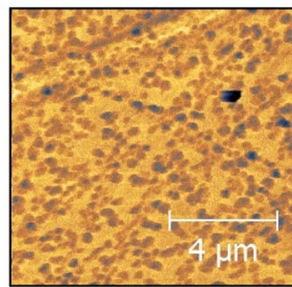

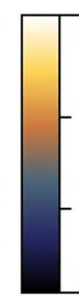

$1.32 \mathrm{~V}$

1.25

1.20

1.15

1.09

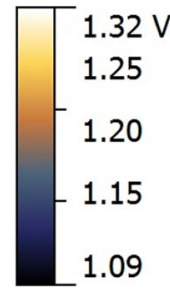

Figure 3. Surface topography A and C and VPD B and D of A199.99_100 V and A199.5_100 V, respectively. shows some more pronounced height steps at the oxide-metal interface (Figure 2B).

AFM-SKPFM.-The AFM-SKPFM analysis of the grown barrier oxides provides information about the surface topography and, more importantly, about the charge distribution at the oxide surface. Selected AFM surface topographies on anodized A199.99_100 V and A199.5_100 V substrates are shown in Figure 3. The corresponding Volta Potential Difference (VPD) mapps for A199.99_100 V and A199.5_100 V are shown in Figures 3B and 3D. The average VPD values for each anodized substrate are derived from representative areas of $10 \times 10 \mu \mathrm{m}^{2}$. Notably, the lateral variation of the measured VPD over several of such representative analysis areas is a factor of 10 higher for the A199.99 substrates (i.e. $\pm 100 \mathrm{mV}$ ) as compared to the A199.5_100 V substrate (i.e. $< \pm 10 \mathrm{mV}$ ). This indicates the formation of laterally less homogenous oxide layers on the A199.99 substrate of higher purity, which can be correlated with the larger oxide growth rate possibly indicating the formation of a more defective structure of the barrier oxides formed on the A199.99 substrate. The overall roughness of the A199.99 substrate is not significantly higher compared to A199.5 but deformation and some scratches are more difficult to avoid during polishing of the softer material.

The average VPD values of the anodized sample surfaces extracted from SKPFM mappings is plotted as functions of the anodizing voltage in Figure 4. The VPD values increased with increasing $V_{\text {anod }}$ up to $150 \mathrm{~V}$, a trend which was similar for both substrates (with slightly higher values for the A199.5). For $V_{\text {anod }}>150 \mathrm{~V}$, the VPD decreases with increasing $V_{\text {anod }}$ for the Al99.99 substrate, but continues to increase for the A199.5 substrate. According to Evangelisti et al., ${ }^{22}$ VPD of A199.5 samples increased up to $8 \mathrm{~V}$ for an applied voltage of $V_{\text {anod }}=250 \mathrm{~V}$ (after which it also starts to drop at higher $V_{\text {anod }}$ ). Such high VPDs clearly indicated the building-up of an ionic space charge region in the oxide during the anodizing process under the influence of the applied high electrical fields. In general, the detection of such large VPD values cannot be explained by electrochemical double layers or adsorbed dipoles, but typically denote a high density of embedded charges (i.e. ionic space charge regions in the oxide). The observed drop in the VPD at $V_{\text {anod }}>150 \mathrm{~V}$ for the A199.99 substrate and at $V_{\text {anod }}>285 \mathrm{~V}$ for the A199.5 substrate indicate that the anodizing voltage approaches the oxide electrical breakdown potential, $V_{\text {bd }}$. However, the breakdown potential is commonly defined as the potential at which the oxide layer cannot grow anymore (electrical breakdown) due to the presence of current leakage through nanoscale defects (as related to the initiation of local sparking in the anodizing process). However, the observed maximum in the measured curves of VPD versus $V_{\text {anod }}$ does not correspond to the actual oxide electrical breakdown potential, but rather reflects the maximum anodizing voltage that can be applied for achieving the most dense and compact barrier oxide layer with the most pronounced residual ionic space charge regions. That the electrical breakdown had not yet reached at the tested potentials is indicated by the fact that thickening of the barrier oxide was still possible at higher potentials. ${ }^{22}$ Therefore, the observed maximum in VPD versus anodizing current should not be confused with the electrical breakdown potential $\left(V_{\text {bd }}\right)$ and will be referred to as "ionic charge-recombination-threshold" potential, $V_{\text {recomb }}$, where $V_{\text {recomb }}<V_{\text {bd }}$.

More compact and less defective barrier oxide layers can withstand higher applied electric fields during the anodizing process and thus accumulate more pronounced ionic space charge regions in the oxide prior to electrical-field-induced breakdown. Analogously, redistribution of accumulated ionic charges across the oxide depth should be also more difficult in dense, defect-free oxides. From the SKPFM analysis, highly compact and less-defective barrier oxides with pronounced residual ionic space charge regions are produced on the A199.5 substrate supporting the observation of lower oxide growth rate of $11.8 \AA / \mathrm{V}$ on this substrate purity. Besides, for $V_{\text {anod }}>V_{\text {recomb }}$, the barrier oxide formed will become less homogenous and moredefective with less pronounced residual ionic space charge regions, as reflected by the VPD drop. The dissimilar trends in VPD versus $V_{\text {anod }}$ for the two substrate purities indicate pronounced differences in the structural defect level of the grown barrier oxides, i.e. the distribution

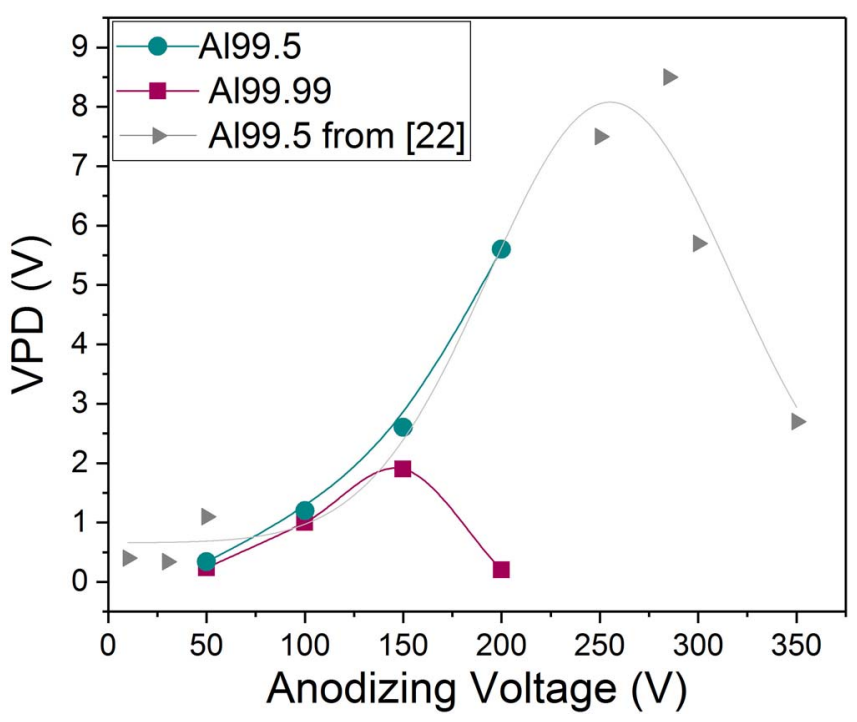

Figure 4. Surface potentials (VPD) obtained for both purity substrates when anodized at different potentials. 
of ionic charges (cation and anion profiles) and the defect concentrations. For crystalline oxide, this could be interpreted in terms of different levels of vacancies and interstitials, but these are concepts that cannot directly be used in the case of the amorphous anodic oxides on aluminum.

Photoelectrochemical and photoluminescence spectroscopies.Photoelectrochemical (PEC) spectroscopy provides useful knowledge regarding the potential barrier behavior depicted by semiconductors in contact with an electrolyte, which, in turn, should be strongly affected by the presence of impurities, oxide defect concentration, etc. ${ }^{34-37}$ The photoelectrochemical spectra obtained for the anodized A199.5 and A199.99 samples are presented in Figure 5A. Oxides grown on both type of substrates exhibited the low photocurrent intensities characteristic of amorphous oxides but still with current maxima close to the $\mathrm{mA} / \mathrm{cm}^{2}$ range in the case of the A199.99 anodic samples. Compared to crystalline structures, the lower photocurrent intensities generally displayed by amorphous semiconductors are explained by the different mechanisms through which the charge carriers are transported within the oxide layer and the resulting electron-hole recombination probabilities. ${ }^{38}$ For crystalline oxides, charge carriers are generated in a continuous energy range and display higher drift mobility and low recombination probabilities. In contrast, charge carriers generated from localized states within the energy gap characteristic of amorphous oxides present poor mobility and are easily recombined. ${ }^{38,39}$

Although the bandgap (BG) energy of amorphous $\mathrm{Al}_{2} \mathrm{O}_{3}$ is reported at about $6.5 \mathrm{eV},{ }^{40}$ the current PEC analysis indicates evident photoresponses at sub-gap energies in the anodically grown barrier oxide layers. For wide bandgap semiconductors, such as $\mathrm{Al}_{2} \mathrm{O}_{3},{ }^{41}$ the observed photocurrents at energy levels below the expected bandgap energy typically originate from internal photoemission of e/h pairs from the metal Fermi level into in-gap states in the oxide layer, following the classical Fowler behavior. ${ }^{37,42,43}$ In fact, both substrate purities display significant photocurrents at excitation energies between 2.5 and $5.5 \mathrm{eV}$. This implies that optical excitation in this energy range can generate electron-hole pairs, ${ }^{44}$ which are effectively separated and result in the measured photocurrents. The lack of long-order characteristic of amorphous oxides generates located energy states within the forbidden energy region (midgap states) because of the only partial overlapping of the electronic wavefunctions. ${ }^{38,39}$ For both substrate purities, the anodic oxides show lower photocurrent intensities for thicker oxide layers. This could be related to $(i)$ increased effective energy barriers for injection of photoinduced charge carriers from the Al substrate into the oxide layers and/or to (ii) decreased structural defect densities with increasing layer thicknesses.

Based on the experimental findings by ellipsometry, SEM of oxide cross sections and especially AFM-SKPFM, it may be assumed that the lower photocurrent intensities observed at higher anodizing voltages is related to the level of structural defects. A denser, less defective oxide induces a lower density of in-gap states in the barrier oxide layers grown at higher anodizing voltages (up to the previously defined ionic charge recombination threshold potential). ${ }^{27}$ The relevance of the defect density on the measured PEC photocurrents is indeed highlighted by the equal photocurrents displayed by the A199.99_150V and A199.99_200V samples (Figure 5A). Considering the larger layer thickness obtained for A199.99_200 V, the similar photocurrents observed for both anodizing conditions should be attributed to the different oxide defect amounts within the A199.99_200V sample. In fact, this is fully consistent with the distinct behavior observed for this sample during the anodic grown and the SKPFM (Figures 1 and 4).

The photoelectrochemical response of the samples can be understood by the relation $\left(\mathrm{I}_{\mathrm{ph}} \mathrm{hv}\right)^{\mathrm{n}} \alpha\left(\mathrm{hv}-\mathrm{E}_{\mathrm{th}}\right)$ where $\mathrm{I}_{\mathrm{ph}}$ is proportional to the absorption coefficient, $h v$ is the photon energy, $\mathrm{E}_{\mathrm{th}}$ is the threshold energy and indirect electronic transitions characteristic of amorphous materials $(n=0.5)$ are assumed. Figure 5B show the Tauc's plot obtained for both purities from which $\mathrm{E}_{\mathrm{th}}$ about $2.1 \pm 0.1$ and $2.3 \pm 0.1 \mathrm{eV}$ were extracted for the A199.5 and A199.99 substrates, respectively. The similar onset $\left(\mathrm{E}_{\mathrm{th}}\right)$ energies, similar minimal ener-
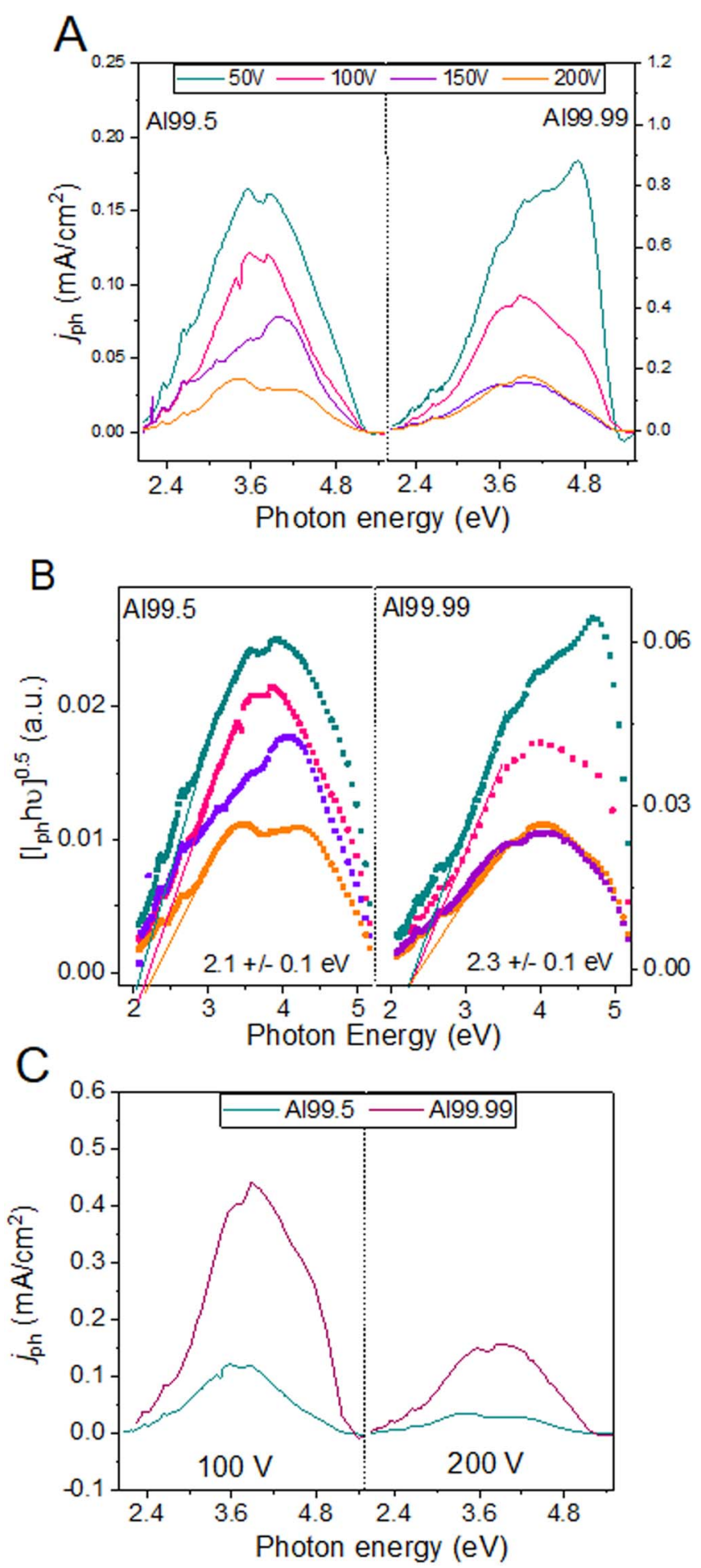

Figure 5. A) PEC spectra obtained for A199.5 and A199.99 when anodized at different potentials; B) Tauc's plot C) Comparison between both purities when anodized at $100 \mathrm{~V}$ and $200 \mathrm{~V}$.

gies for injecting electrons in the oxide energy states, suggest certain similarities between the in-gap states developed on both oxide types. At energies lower than the threshold energies $\mathrm{E}<\mathrm{E}_{\mathrm{th}}$, some differences were observed in the shape of the photocurrent onsets. For the A199.5 samples, steeper current onsets were observed while the A199.99 showed certain photocurrent intensities extended until lower energies. According to the Mott and Davis model, amorphous materials exhibit localized states close to the valence and conduction 
A

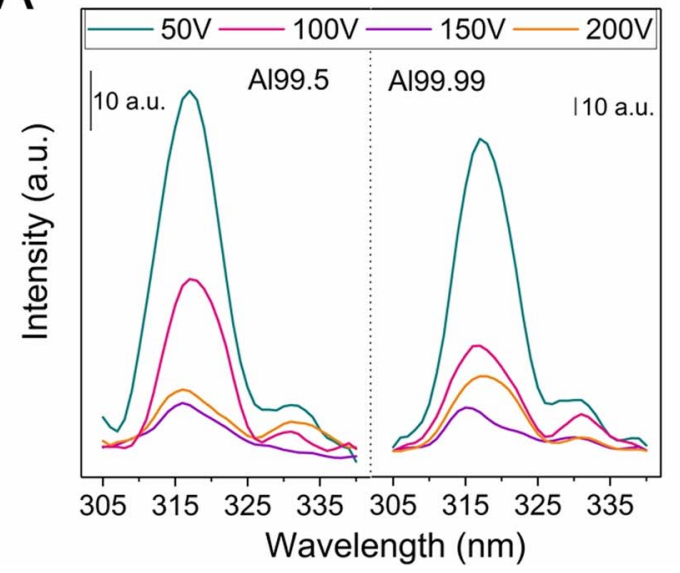

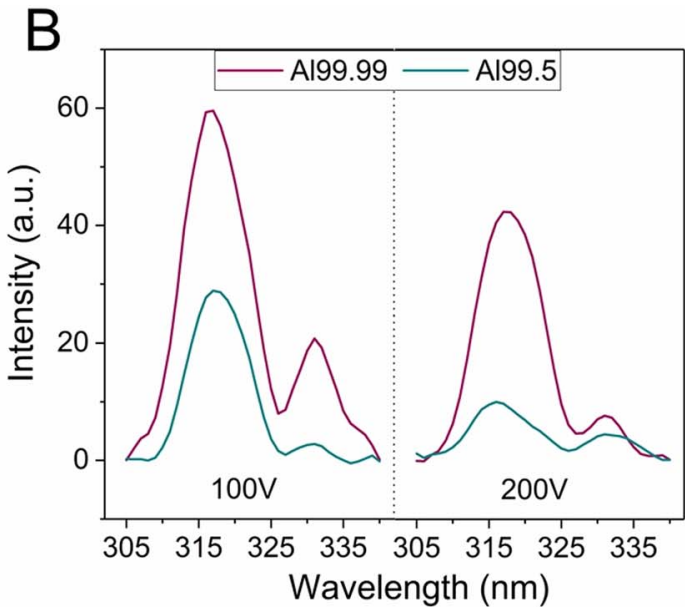

Figure 6. PL spectra obtained using excitation energy at 260nm: A) Al99.99 samples and B) Comparison between both purities when anodized at 100V and 200V.

mobility edges. ${ }^{38}$ The accentuated photocurrent tails noted for the anodized A199.99 samples, which have been associated with optical transitions at $\mathrm{E}<\mathrm{E}_{\mathrm{th}}{ }^{39}$ could also represent easier charge carriers mobility for these excitation energies and then, variations in the in-gap states.

Figure 5C compares the PEC spectra obtained for both A199.5 and A199.99 when anodized at $100 \mathrm{~V}$ and $200 \mathrm{~V}$. Considering the slightly larger oxide layer thickness of the A199.99 anodized samples, larger resistances toward charge transfer through the oxide layer are in turn, expected. In contrary, the Al99.99 samples always displayed significantly higher photocurrents than A199.5 independent of the anodizing voltage (note the different scales used for the different purities in Figure 5A). The observed trend is therefore clearly not related to a thickness effect but accounts for higher structural defect populations developed within the A199.99 barrier oxides, with respect to the A199.5. It could then be suggested that, the slower oxide growth rates detected in the oxides growth on the A199.5 substrate resulted in more compact barrier layers with smaller amounts of point scale defects (e.g. vacancies) and hindered ionic charge carrier transport abilities.

The type and concentration of defect sites embedded in the anodized $\mathrm{Al}_{2} \mathrm{O}_{3}$ oxides have therefore been further related to the photoluminescent (PL) emissions observed when alumina is exposed to ultraviolet radiation to correlate the defect identification with two different physical phenomena. The photoluminescent emissions are associated with defective sites and, although their origin is not always fully identified, it is known that the oxide defect luminescence behavior is determined by the short-range structural properties and not by the long-range order. ${ }^{45}$ In fact, the local short range order in the amorphous oxides grown by anodizing should resemble the short range order in the crystalline $\mathrm{Al}_{2} \mathrm{O}_{3}$ polymorphs. ${ }^{46}$ In general, the PL spectra of $\mathrm{Al}_{2} \mathrm{O}_{3}$ oxides exhibit a broad emission band (260-600 nm) composed of different contributions attributed to defective centers such as oxygen vacancies and/or to impurities. ${ }^{23}$ Differences in defective centers concentration in $\mathrm{Al}_{2} \mathrm{O}_{3}$ oxide films can be directly correlated with emission band intensity. According to the literature, the main intrinsic defects characteristic of $\mathrm{Al}_{2} \mathrm{O}_{3}$ oxides are $\mathrm{F} / \mathrm{F}^{+}$centers and $\mathrm{Al}^{\delta+}$ cations in interstitials positions or distorted local coordination with different oxidation states of $\mathrm{Al}_{2} \mathrm{O}_{3} .{ }^{25,47,48}$ While $\mathrm{F}$ centers and $\mathrm{C}$ species related emissions are reported in literature at about $420 \mathrm{~nm}$, PL emissions at about $320 \mathrm{~nm}(3.8 \mathrm{eV})$ are mostly ascribed to oxygen vacancies with one electron trapped which emission $\left(\mathrm{F}^{+}\right.$centers $)$and interstitial $\mathrm{Al}$ cations.

Among the identified defects, the higher $\mathrm{F}^{+}$centers stability and presence in $\mathrm{Al}_{2} \mathrm{O}_{3}$ oxides is attributed to the strong repulsion of an electron pair localized in an oxygen vacancy ( $\mathrm{F}$ centers). ${ }^{49}$ Because of their higher stability and concentration, $\mathrm{F}^{+}$centers have been interpreted to be representative for extrapolating the overall defect con- centrations of the anodic samples. Figure 6A shows the measured PL spectra in the wavelength range from $310-340 \mathrm{~nm}$. For the studied amorphous $\mathrm{Al}_{2} \mathrm{O}_{3}$ barriers oxides, two different emission edges, centered at 317 and $330 \mathrm{~nm}$ are identified being those probably related to locally distorted coordination spheres of interstitial $\mathrm{Al}$ cations and $\mathrm{F}^{+}$ centers, respectively. ${ }^{28} \mathrm{Up}$ to $150 \mathrm{~V}$, increasing anodizing voltages for both purities led to emission intensity decrements indicating lowered defective site concentrations embedded within the oxide and correlating with the previous photoelectrochemical current decreasing at higher anodizing voltage.

Also, the oxides grown on both substrate purities showed slight luminescence intensity increase at $200 \mathrm{~V}$ indicating larger amounts of defect centers. This suggests that $V_{\text {anod }}>150 \mathrm{~V}$ enhances the creation of defects for both substrate purities during the anodizing process. Although this intensity trend is detected for both purities, a much more pronounced luminescence band intensity was measured for the oxide grown on high purity samples. However, for the A199.5_200V, a slight defect centers increase is uniquely observed by PL spectroscopy, whereas PEC and SKPFM measurements continue to indicate the growth of the dense layer. In this case, it can be postulated that a small structural defect density increase in a dense oxide is insufficient to generate ionic charge recombination until a certain defect threshold is reached. Still, this structural defect level increase is the precursor of the $\mathrm{V}_{\text {recomb }}$ occurring at higher anodizing voltages. It also shows that the information on the defect level obtained by PL (optical detection) and PEC (electronic charge detection) are slightly different even if the trends are perfectly consistent up the $150 \mathrm{~V}$ anodizing voltages. For the oxide grown on A199.99 samples, the increase of the defect concentration level for the anodizing processes at $200 \mathrm{~V}$ is clearly observable and an overall agreement between the different characterization results is obtained. Indeed, going beyond the $V_{\text {recomb }}$ resulted in remarkably higher defect concentrations as evidenced by the significantly larger PL band emissions as well as the relative lower resistance to the ionic and charge carrier transport (AFM-SKPFM and PEC spectroscopy, respectively).

Figure 6B compares the emission bands exhibited for both types of substrate when anodized at voltages of 100 and 200V. It can be observed that the A199.99 samples showed much higher band intensities compared to the homologous A199.5 substrates anodized at similar voltages. In agreement with the higher PEC photocurrents and PL emission intensities detected for the A199.99, it can be confirmed that anodizing processes performed on the high purity substrate induced the formation of higher defective oxides in comparison to the A199.5 ones. Although the photocurrents displayed by amorphous oxides are lower than those of crystalline structures, the increase of the concentration of defective sites $\left(\mathrm{F}^{+}\right.$centers/ $\left.\mathrm{Al}_{\mathrm{i}}\right)$ in amorphous oxides also leads to larger photocurrent intensities. The higher amount of e-h pairs 

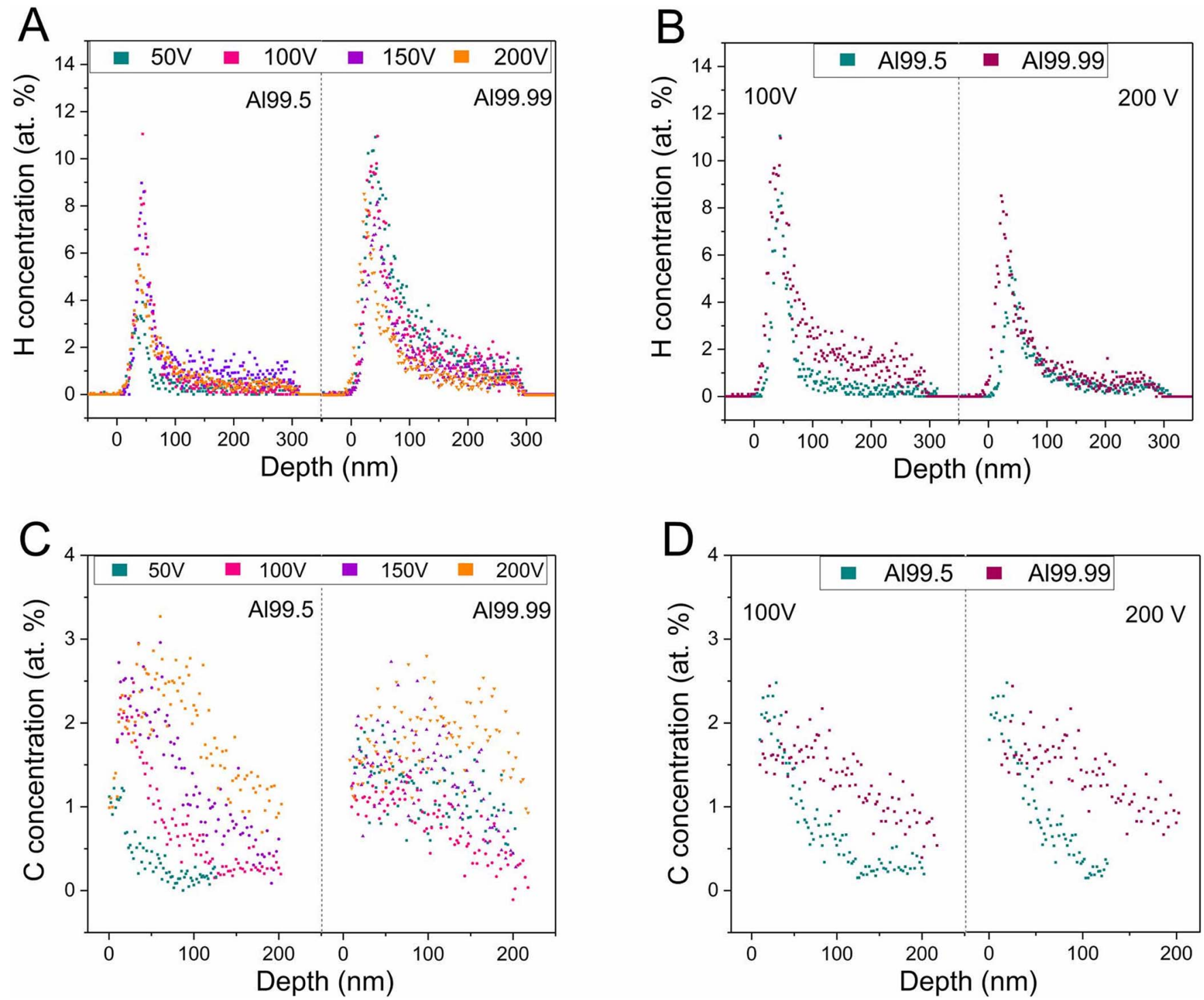

Figure 7. A) H profiles for A199.99 and A199.5 substrates anodized at different voltages; B) H profiles obtained for A199.5 and A199.99 substrates anodized at 100 and 200V; C) C profiles for A199.99 and Al99.5 substrates anodized at different voltages; D) C profiles obtained for A199.5 and Al99.99 substrates anodized at 100 and $200 \mathrm{~V}$.

effectively separated within the oxides grown on the Al99.99 can be explained by changes in the amount of charge carriers generated and/or on the degree of confinement and probability of recombination. ${ }^{38,39}$ Both possibilities, which could indeed coexist, can explain the higher amounts of e-h pairs effectively separated on the Al99.99 samples. The different defect concentrations detected on the oxides grown on substrates of both purities also provoked changes on the configuration and/or density of midgap states constituted for each oxide. The combination of the two techniques allows possible artefacts of the PEC signal intensity related to larger oxide thickness to be discarded and provides a clear correlation of the measurements with defect density.

RBS, ERDA and FT-IR spectroscopies.-RBS and ERDA measurements along with FT-IR spectroscopy should established useful relationships between the structural defect population and the $\mathrm{H} / \mathrm{C}$ species contained within the anodically grown $\mathrm{Al}_{2} \mathrm{O}_{3}$ oxides.

For both substrate purities, the hydrogen $(\mathrm{H})$ profiles obtained by RBS measurements are presented in Figure 7A. The shape of the $\mathrm{H}$ depth-distribution profile in the oxide layers was similar for all cases studied. The $\mathrm{H}$ concentration was relatively low and shallow at larger depths within the bulk oxide, but very steadily increased toward the oxide surface, reaching local $\mathrm{H}$ concentrations as high as about 10-12 at.\%. Compared to the A199.99 substrate, the anodized A199.5 substrates clearly exhibited considerably sharper in depth $\mathrm{H}$ profiles, i.e. the drop in the $\mathrm{H}$ concentration from the surface was more pronounced, which implies a lower concentration of $\mathrm{H}$ in the interior of the barrier oxide. Thus, significantly higher $\mathrm{H}$ concentrations were detected in the oxide layers grown on the A199.99 substrate (for all studied anodizing voltages). Figure 7B shows a comparison of the measured H profiles for the A199.5 and A199.99 substrates at two different anodizing voltages of 100 and $200 \mathrm{~V}$, which also clearly shows a broader tail for the A199.99_100 V substrate as compared to the A199.5_100 V substrate. Moreover, Figure 7B clearly reflects that the nominal concentration of incorporated the $\mathrm{H}$ species decreased with increasing anodizing voltage, in accordance with the lower structural defect concentration of the barrier oxides grown at higher anodizing potentials.

The measured carbon (C) concentration-depth profiles of the anodized A199.5 and A199.99 substrates, obtained by ERDA, are presented for the different anodizing potentials in Figure 7C. Lower C amounts were incorporated into the grown oxide barrier as compared to $\mathrm{H}$-species. The decrease of the $\mathrm{H}$ and $\mathrm{C}$ amounts in deeper positions 

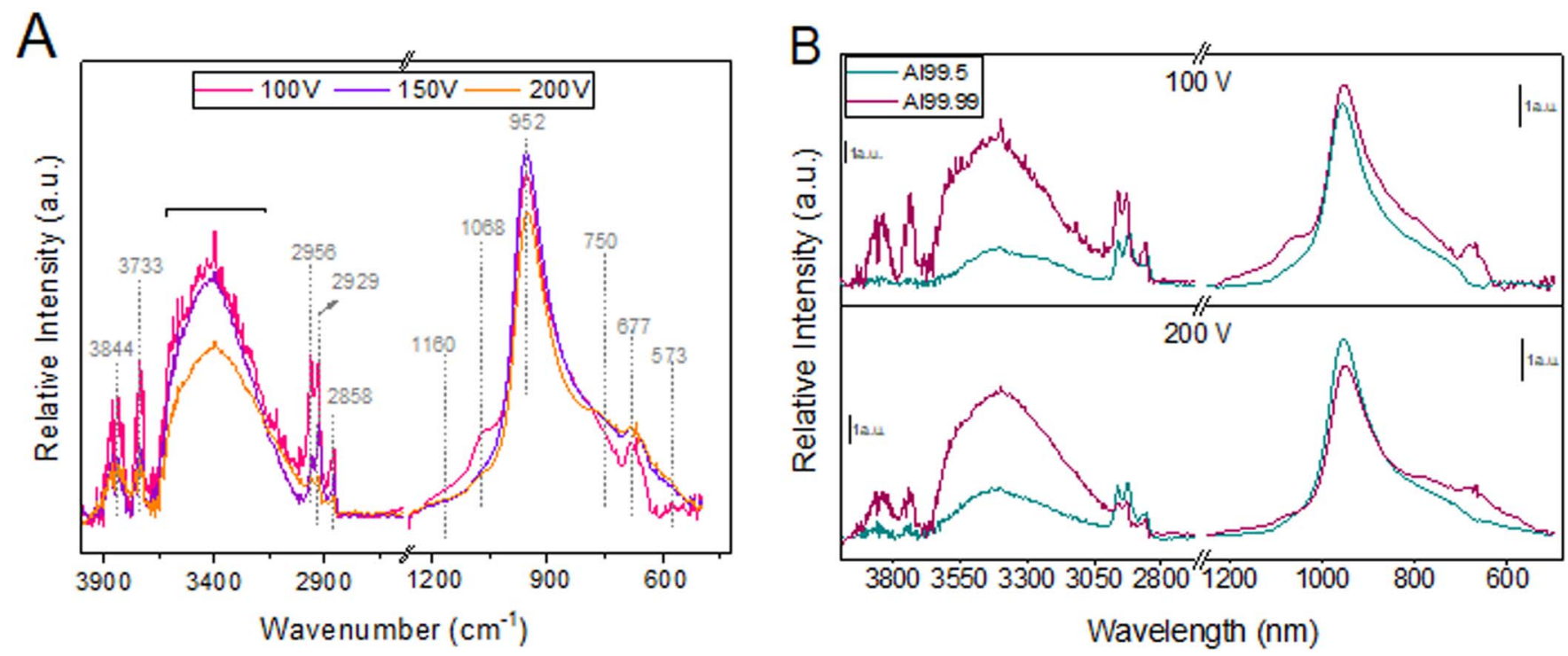

Figure 8. FT-IR spectra obtained for the anodic samples: A) A199.99; B) Effect of the substrate purity when anodized at 100 and $200 \mathrm{~V}$.

of the barrier oxides suggests the presence of density and defect concentration gradients from the surface to the bulk of the oxide layer. For higher anodizing voltages, no evident changes on the $\mathrm{C}$ concentrations were observed for both purity substrates. However, weak increases of $\mathrm{C}$ species with increasing $\mathrm{V}_{\text {anod }}$ cannot be ignored, especially for the A199.5. The oxide layer densification and diminution of the structural defect density detected for both purity substrates for increasing $\mathrm{V}_{\text {anod }}$ is accompanied by a decrease of the $\mathrm{H}$ amounts. As for the $\mathrm{H}$ concentration, the $\mathrm{C}$ impurity concentration in the barrier oxides is also higher for the A199.99 substrate (Figure 7D).

Concerning the chemical nature of the impurities present in the anodized oxide, Figure 8A shows the FT-IR spectra obtained in reflection mode for the A199.99 substrate. No spectra could be obtained for the samples anodized at $50 \mathrm{~V}$, most probably due to the small oxide layer thicknesses. In terms of observed species in the oxide, similar FT-IR spectra were found for both types of substrate. All the samples exhibited bands typically associated with stretching vibrations of $\mathrm{OH}$ (3700-3000 $\mathrm{cm}^{-1}$ ) and $\mathrm{CH}$ (around $2900 \mathrm{~cm}^{-1}$ ) species. ${ }^{23,50}$ In addition, additional bands attributed to $\mathrm{C}=\mathrm{C}, \mathrm{C}=\mathrm{O}\left(1200-1100 \mathrm{~cm}^{-1}\right)$ and OCO $\left(900-500 \mathrm{~cm}^{-1}\right)$ species were observed in the region from 1200 to $500 \mathrm{~cm}^{-1} .51,52$ Some bands in the range 800 to $500 \mathrm{~cm}^{-1}$ associated with stretching vibrations of $\mathrm{Al}-\mathrm{O}$ bonds in octahedral (750-500 $\left.\mathrm{cm}^{-1}\right)$ and tetrahedral coordination $\left(900-750 \mathrm{~cm}^{-1}\right)$ were also observed. It has to be noted that, although the anodized $\mathrm{Al}_{2} \mathrm{O}_{3}$ oxides were amorphous, local Al-O short ordered clusters with similar vibrational properties than crystalline compounds are also expected.$^{53}$ In agreement with the $\mathrm{H}$ decrease detected in $\mathrm{RBS}$, the $\mathrm{OH}$ and $\mathrm{CH}$ band intensities decrease with increasing anodizing voltage. As claimed from ERDA measurements, the trends of the C-containing species (with edges observed at ca. 1160, 1068, 952, 780 and $677 \mathrm{~cm}^{-1}$ ) awere less clear for the different $\mathrm{V}_{\text {anod. }}$. Figure $8 \mathrm{~B}$ compares the measured FT-IR spectra of the A199.5 and A199.99 substrates at anodizing voltages of $100 \mathrm{~V}$ and $200 \mathrm{~V}$. For both anodizing potentials, the $\mathrm{OH}-$ related signals in the range of $3700-3000 \mathrm{~cm}^{-1}$ were significantly higher for the anodized A199.99 substrates, in accord with the higher $\mathrm{H}$ content in the respective barrier oxide layers.

\section{Discussion}

An overall picture of the substrate effect on the anodized oxide growth and structural defect distribution is given in the Figure 9 based on the oxide cross sections of Figure 2B. As a general statement, both purity substrates generated barrier oxide layers with thickness determined by the applied voltages: the higher the anodizing voltage, the thicker the oxide layer. Compared to Al99.99 substrate purity, thinner barrier oxides were grown on the A199.5 substrates on polished as well as electropolished surfaces. This observation points out the impact of the substrate purity on the anodized oxide growth, density, defect structure and ionic transport properties on the oxide under high electrical fields. The main impurities contained in the A199.5 substrate are $0.2 \% \mathrm{Fe}$ and $0.2 \% \mathrm{Si}$. Enhanced growth rates have been attributed to faster $\mathrm{Al}$ ionic migration in $(0.2 \%) \mathrm{Fe}$-doped $\mathrm{Al}_{2} \mathrm{O}_{3} .{ }^{54} \mathrm{On}$ the other hand, smaller anodic oxide growth rates have been related to the presence of $\mathrm{Si}$ in $\mathrm{Al}-\mathrm{Si}$ alloys ${ }^{33}$ where, for larger $\mathrm{Si}$ contents starting at $4 \%$, Si-oxide enriched zones at the metal-metal oxide interfaces were observed. The RBS results on oxides grown on A199.5 substrates showed the presence of a small amount of extra metallic species concentrated close to the metal interface. Similarly, for pure
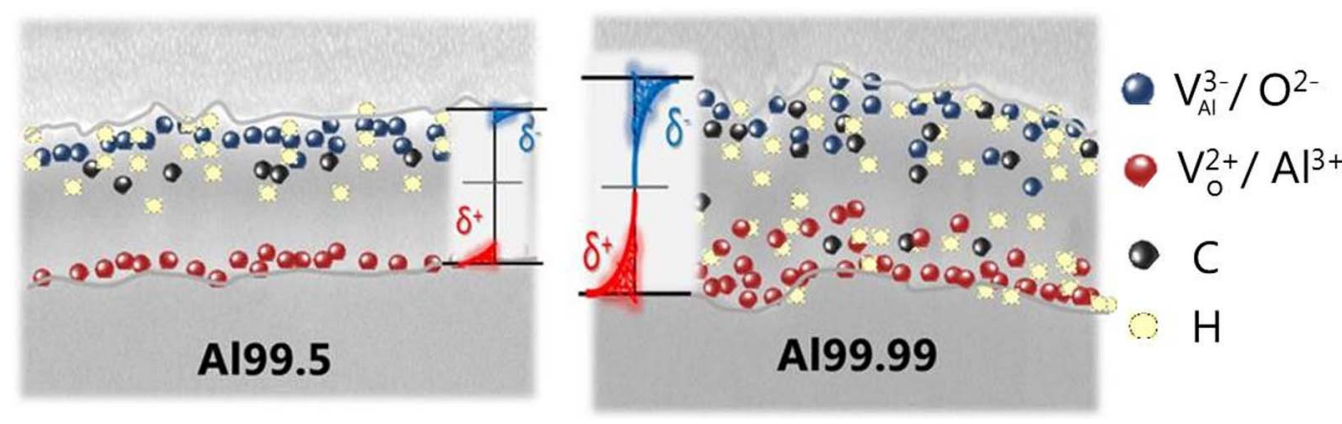

Figure 9. Schematic description of the of substrate purity influence on the anodic barrier $\mathrm{Al}_{2} \mathrm{O}_{3}$ ionic defect structure. 
$\mathrm{Ti}$ and Ti-Si alloys (6\% Si), lower photoelectrochemical currents and higher breakdown potentials were attributed to the presence of $\mathrm{Si}$ at the interface and related to highly stoichiometric oxides with lower oxygen vacancies concentration. ${ }^{55}$ Therefore, the lower growth rates observed for A199.5 could be attributed to the presence of $\mathrm{Si}$ as impurities underlining that remarkably different oxide properties can be indeed achieved by incorporating even submonolayer amounts of cationic species within barrier $\mathrm{Al}_{2} \mathrm{O}_{3}$ layers, also in line with previous findings. ${ }^{33}$

Related to the different oxide growth rates on the two type of $\mathrm{Al}$ purity, a difference in the ionic migration properties resulted in differences on the VPD (dominated by the ionic space charge layer formation in the oxide) measured by AFM-SKPFM. When the anodizing voltages were increased, the progressive increase in the VPD noted for the A199.5 samples could be explained by anionic and cationic "like" vacancies generated at the $\mathrm{M} / \mathrm{O}$ and O/electrolyte interphases, respectively. The hindered ionic transport processes, which led to thinner A199.5 oxide layers with respect to A199.99 substrates, results in confining more the accumulated ions at the interfaces, impeding the ionic charge recombination and inducing an increased VPD. In contrast, easier ionic mobility and charge recombining processes within a more structural defective oxide matrix accounts for the lower measured VPD and strong decrease observed for A199.99_200V. When higher voltages were applied on the A199.99 substrates, favored driving force for ionic migrations allowed for recombination processes in the presence of larger amount of structural defects and led to the observed VPD decrease. Thus, although the oxide was in an overall charge neutrality condition, different oxide density and defect levels were generated depending on the migration mechanisms. In case of a denser oxide, this will result in pronounced ionic space charge localization at interfaces identified by AFM-SKPFM.

For compact barrier oxides, migration processes occurring under high electrical fields will determine the defect and impurity concentrations within the oxide and consequently, the structural and electronic properties. The electronic charge transport capability through the oxide, i.e. the displayed decreasing photocurrents as a function of anodizing voltage in PEC spectroscopy, is correlated to the higher layer thickness and to the lower defect density, which will determine the electron-hole pair generation and annihilation. For similar substrates and conditions, Evangelisti et al. ${ }^{22}$ experimentally observed anodic $\mathrm{Al}_{2} \mathrm{O}_{3}$ oxide densification, supported by DFT modelling of amorphous oxide, when the anodizing voltages were increased. In agreement to the density decrease with the $\mathrm{V}_{\text {anod }}$, higher anodizing voltages also led to lower emission intensities in PL spectroscopy indicating defect concentration decrease. In terms of extrinsic species, no significant $\mathrm{C}$ content variations were measured in ERDA while FTIR and RBS undoubtedly indicated that larger anodizing voltages also decreased the amount of $\mathrm{H}$ species present in the $\mathrm{Al}_{2} \mathrm{O}_{3}$ barrier layers for both purity substrates. It should be highlighted that, although the $\mathrm{C}$ species affect the oxide luminescence emissions, considering the absence of significant changes of the $C$ contents with anodizing voltage and the luminescence emission range measured $(\mathrm{C}$ species emit around $420 \mathrm{~nm}$ ), the large changes observed on the PL band intensities should be uniquely correlated to variations on the $\mathrm{H}$ and/or defect concentrations.

The impact of the substrate purity in the obtained oxide properties can also be clearly established. Indeed, qualitative and clear differences were detected between both $\mathrm{Al}$ purities for the entire anodizing voltage range considered. The higher photocurrents and band intensities displayed by the A199.99 samples for PEC and PL spectroscopies clearly indicated higher structure defect site concentrations. The higher ionic migration rate that led to larger oxide thicknesses exhibited by the A199.99 substrate resulted in lower density and highly disordered oxides with higher defect populations. Larger electronic charge generation and ionic transport processes as well as integration of extrinsic species within the oxide layer then resulted for the oxide grown on A199.99 substrate. This statement is, in fact, strongly supported by the larger amount of $\mathrm{H}$ and $\mathrm{C}$ species detected in the A199.99 samples. In contrast, the slower oxide growth rate obtained for the A199.5 substrate could be related to the lower effective electrical field caused by the accumulation of the Si species at the M/O interface and resulted in the constitution of highly ordered barrier layers with lower defect sites and lower amount of $\mathrm{H}$ and $\mathrm{C}$ in the bulk of the oxide. The differences observed in oxide structural defect levels between these two substrate purities anodized in the same electrolyte and conditions, indicates that $\mathrm{H}$ integration is a consequence of the oxide defect formed during anodizing. Often in the literature, the impurities from the electrolyte integrated in the oxide are considered to be responsible for the generation of defects in the grown oxide. The outcomes obtained in this study underline the opposite: highly defective oxides favor the incorporation of extrinsic species coming from the electrolyte.

\section{Conclusions}

In this work, two different aluminum metal purities, $99.5 \%$ and $99.99 \%$, have been used as substrates for growing barrier $\mathrm{Al}_{2} \mathrm{O}_{3}$ layers via anodizing processes performed at different voltages in citric acid. The metallic substrate strongly determined the properties the barrier oxides even for this slight impurity level difference. In fact, the importance of the substrate purity on the anodized oxide structure was reflected by the different ionic charge recombination voltages, layer thicknesses, structural defect concentration and extrinsic impurity integration. Compared to A199.5 substrate, the A199.99 ones exhibited faster oxide growth rates, larger layer thicknesses and lower ionic charge recombination threshold potentials $\left(\mathrm{V}_{\text {recomb }}\right)$. In concordance to the more disordered and rough oxide layers, larger amounts of defects sites and easier incorporation of extrinsic species coming from the electrolyte were also detected for the higher purity substrate.

Potential mapping by AFM-SKPFM indicated larger lateral variations of the measured VPD for the A199.99 substrates as compared to the A199.5 substrate which indicated the formation of less homogenous oxide layers on the A199.99 substrate. The considerably lower $\mathrm{V}_{\text {recomb }}$ noted for the A199.99 substrate with respect to the A199.5 one, was associated with a less dense, more defective oxide formation and consequent easier ionic space charge recombination. In agreement, compared to the A199.5 purity substrate, larger PEC photocurrents and PL emission intensities observed for the anodic oxide grown on the A199.99 substrate further point out the higher structural defect amount. RBS and ERDA measurements indicated the incorporation of light impurities species $(\mathrm{C}$ and $\mathrm{H})$ from the electrolyte during the oxide growth. The total $\mathrm{H}$ and $\mathrm{C}$ content within the oxide barrier layer was considerably higher for the oxides grown on A199.99 substrates.

The experimental findings emphasize the significant effect of substrate impurities on the resulting barrier oxide properties of anodized oxides. They also indicate that very different oxide structural defect levels can be obtained during anodizing with the substrate considered to play a larger role compared to the electrolyte species that are integrated as a consequence of formed defects. The present study represents a step forward toward the fundamental understanding of why, contrary to the intuition, purer $\mathrm{Al}$ substrates induce highly defective barrier oxides. A significant contribution to this understanding can be obtained by the new combination of employed characterization techniques (AFM-SKPFM, PEC and PL) which constitutes a promising methodology for investigating very fine oxide structural differences affecting the $\mathrm{Al}_{2} \mathrm{O}_{3}$ barrier properties.

\section{Acknowledgments}

The authors thank Dr. F. La Mattina and Prof. Nüesch's group at Empa for the fruitful discussions. The authors also acknowledge Dr. E. Hack for the ellipsometry measurements. This work has been performed within the frame of the National Center of Competence in Research (NCCR) "Materials' Revolution: Computational Design and Discovery of Novel Materials (MARVEL)" of the Swiss National Science Foundation. 


\section{ORCID}

Miriam González-Castaño (i) https://orcid.org/0000-0003-2575-8398

Claudia Cancellieri (D) https://orcid.org/0000-0003-4124-4362

\section{References}

1. I. Levin and D. Brandon, J. Am. Ceram. Soc., 81, 1995 (2005).

2. D. H. Trinh, K. Back, G. Pozina, H. Blomqvist, T. Selinder, M. Collin, I. Reineck, L. Hultman, and H. Högberg, Surf. Coatings Technol., 203, 1682 (2009).

3. G. W. Critchlow and D. M. Brewis, Int. J. Adhes. Adhes., 16, 255 (1996)

4. C. R. Martin, Science, 266, 1961 (1994).

5. R. A. Mirzoev, A. D. Davydov, D. K. Kurmyalevskaya, A. N. Bazylyk, and S. I. Vystupov, Electrochim. Acta, 184, 214 (2015)

6. S. Akiya, T. Kikuchi, S. Natsui, N. Sakaguchi, R. O. Suzuki, and Elsevier Ltd, 2016.

7. M. González-Castaño, S. Ivanova, T. Ioannides, M. A. Centeno, and J. A. Odriozola, Catal. Sci. Technol., 7, 1556 (2017).

8. D. Veys-Renaux, N. Chahboun, and E. Rocca, Electrochim. Acta., 211, 1056 (2016).

9. J. Chen, M. Yao, and X. Yao, J. Electron. Mater, 45, 892 (2016).

10. D. Dixon, D. J. Babu, J. Langner, M. Bruns, L. Pfaffmann, A. Bhaskar, J. J. Schneider, F. Scheiba, and H. Ehrenberg, J. Power Sources, 332, 240 (2016).

11. J. W. Diggle, T. C. Downie, and C. W. Goulding, Chem. Rev., 69, 365 (1969).

12. G. Patermarakis, H. Karayianni, K. Masavetas, and J. Chandrinos, J. Solid State Electrochem., 13, 1831 (2009).

13. K. Shimizu, G. M. Brown, H. Habazaki, K. Kobayashi, P. Skeldon, G. E. Thompson, and G. C. Wood, Electrochim. Acta, 44, 2297 (1999).

14. G. C. Wood, J. Electrochem. Soc., 143, 74 (1996).

15. k. Delijić, B. Markoli, and N. Iztok, Met. Mater. Eng., 20, 217 (2014).

16. H. Habazaki, K. Shimizu, P. Skeldon, G. E. Thompson, G. C. Wood, and X. Zhou, Trans. IMF, 75, 18 (1997).

17. F. A. Kroger, Ann. Rev. Mater. Sci., 7, 449 (1977).

18. P. Y. Hou, J. Am. Ceram. Soc., 86, 660 (2003).

19. C. K. Chung, D. Dhandapani, C. J. Syu, M. W. Liao, B. Y. Chu, and E. H. Kuo, J. Electrochem. Soc., 164, C121 (2017)

20. L. Domingues, J. C. S. Fernandes, M. Da Cunha Belo, M. G. S. Ferreira, and L. Guerra-Rosa, Corros. Sci., 45, 149 (2003).

21. G. E. Thompson, L. Zhang, C. J. E. Smith, and P. Skeldon, Corrosion,. 55, 1052 (1999).

22. F. Evangelisti, Ambrosio F., A. Pasquarello, O. Guseva, R. Partovi Nia, R. Hauert, E. Hack, L. P. H. Jeurgens, P. Schmutz, and C. Cancellieri, Electrochim. Acta, 224, 503 (2017).

23. S. Stojadinovic, R. Vasilic, Z. Nedic, B. Kasalica, I. Belca, and L. Zekovic, Thin Solid Films, 519, 3516 (2011)

24. J. P. Sullivan, J. C. Barbour, R. G. Dunn, K.-A. Son, L. P. Montes, N. Missert, and R. G. Copeland, Electrochem. Soc. Meet. Bost. MA, 98, 111 (1998).
25. B. C. Bunker, G. C. Nelson, K. R. Zavadil, J. C. Barbour, F. D. Wall, J. P. Sullivan, C. F. Windisch, M. H. Engelhardt, and D. R. Baer, J. Phys. Chem. B, 106, 4705 (2002).

26. N. Kristianpoller, A. Rehavi, A. Shmilevich, D. Weiss, and R. Chen, Nucl. Instrument Methods Phys. Res. Sect. B Beam Interact. with Mater. Atoms., 141, 343 (1998).

27. P. Schmutz and G. S. Frankel, J. Electrochem. Soc., 145, 2285 (1998).

28. M. Natasi, J. W. Mayer, and Y. Wang, Ion Beam Analysis: Fundamentals and Applications, $215 \mathrm{AD}$

29. L. R. Doolittle, Nucl. Inst. Methods Phys. Res. B, 15, 227 (1986).

30. C. Kottler, M. Döbeli, F. Glaus, and M. Suter, Nucl. Instruments Methods Phys. Res. Sect. B Beam Interact. with Mater. Atoms, 248, 155 (2006).

31. N. P. Barradas, C. Jeynes, and R. P. Webb, Appl. Phys. Lett., 71, 291 (1997)

32. Y. Ikuma and R. S. Gordon, J. Am. Ceram. Soc., 66, 139 (1983).

33. C. Cancellieri, F. Evangelisti, T. Geldmacher, V. Araullo-Peters, N. Ott, M. Chiodi, M. Döbeli, and P. Schmutz, Mater. Sci. Eng. B, 226, 120 (2017).

34. E. McCafferty, Corros. Sci., 45, 301 (2003).

35. S. Ikonopisov, Electrochim. Acta, 22, 1077 (1977).

36. F. Di Quarto, C. Gentile, and S. Piazza, J. Electrochem. Soc., 138, 1856 (1991).

37. F. Di Quarto, M. Santamaria, and C. Sunseri, Anal. Methods Corros. Sci. Technol., 18, 697 (2006).

38. F. Di Quarto, S. Piazza, A. Splendore, and C. Sunseri, Proceedings of the symposium on Oxide Films on Metals and Alloys. 182nd Electrochemical Society Meeting in Toronto (Canada), 92-22, 311 (1992).

39. A. Zaffora, M. Santamaria, F. Di Franco, H. Habazaki, and F. Di Quarto, Phys. Chem. Chem. Phys., 18, 351 (2016).

40. A. P. Z. Guo and F. Ambrosio, Appl. Phys. Lett., 109, 62903 (2016).

41. R. H. French, J. Am. Ceram. Soc., 73, 477 (1990).

42. L. M. Castillo and L. M. Peter, J. Electroanal. Chem., 146, 377 (1983).

43. J. S. Helman, Physical Rev. B, 7, 3702 (1973).

44. J. P. H. Sukamto, C. S. McMillan, and W. Smyrl, Electrochim Acta, 38, 15 (1993).

45. C. Feldman and K. Moorjani, APL Tech. Dig., 7, 2 (1968).

46. P. C. Snijders, L. P. H. Jeurgens, and W. G. Sloof, Surf. Sci., 496, 97 (2002)

47. J. Carrasco, N. Lopez, C. Sousa, and F. Illas, Phys. Rev. B, 72, 1 (2005).

48. S. K. Lee, S. B. Lee, S. Y. Park, Y. S. Yi, and C. W. Ahn, Phys. Rev. Lett., 103, 4 (2009).

49. A. I. Surdo, V. A. Pustovarov, V. S. Kortov, A. S. Kishka, and E. I. Zinin, Nucl Instruments Methods Phys. Res. Sect. A Accel. Spectrometers, Detect. Assoc. Equip., 543, 234 (2005)

50. M. González-Castaño, E. Le Saché, S. Ivanova, F. Romero-Sarria, M. A. Centeno, and J. A. Odriozola, Appl. Catal. B Environ., 222, 124 (2018).

51. Y. Yamamoto and N. Baba, Thin Solid Films, 101, 329 (1983).

52. A. Adamczyk and E. Długoń, Spectrochim. Acta Part A Mol. Biomol. Spectrosc., 89, 11 (2012).

53. D. V. Kysil, A. V. Vasin, S. V. Sevostianov, V. Y. Degoda, V. V. Strelchuk, V. M. Naseka, Y. P. Piryatinski, V. A. Tertykh, A. N. Nazarov, and V. S. Lysenko, Nanoscale Res. Lett., 12, (2017).

54. P. A. Lessing and R. S. Gordon, J. Mater. Sci., 12, 2291 (1977).

55. F. Di Quarto, F. Di Franco, C. Monarca, M. Santamaria, and H. Habazaki, Electrochimica Acta, 110, 517 (2013). 